\title{
Controvertida evidencia sobre la eficacia del arándano para la prevención de infecciones urinarias
}

\author{
Controversial evidence about the efficacy of cranberry to prevent urinary tract infections
}

Chih-Hung Wang y col. Archives of Internal Medicine 2012; 172: 988-996.

\section{Objetivos}

Evaluar la eficacia de los productos que contienen arándanos para la prevención de infecciones del tracto urinario (ITU).

\section{Fuente de datos}

MEDLINE, EMBASE y registro de ensayos clínicos (Biblioteca Cochrane), sin restricción de idioma, población o año de publicación.

\section{Selección de estudios}

Ensayos clínicos controlados aleatorizados (ECCA) que hubieran comparado con placebo u otro grupo control, el uso de productos que contienen arándano para la prevención de ITU.

\section{Extracción de datos}

Los estudios seleccionados debían contener información sobre las características de la población incluida, el tipo de intervención, la definición de ITU, el número y las razones de la pérdida de participantes durante el seguimiento. Los datos fueron extraídos por cuatro revisores independientes.

\section{Resultados principales}

El resultado primario fue la incidencia de ITU. Fueron seleccionados diez ECCA que incluyeron un total de 1494 participantes (794 en los grupos asignados al consumo de arándano y 700 , en los grupos controles). La mayoría de los pacientes $(n=982)$ fueron seguidos por seis meses. Se observó una menor incidencia* de ITU en las personas asignadas a los grupos "intervención" (RR 0,62; IC95\% 0,49 a 0,8; I2=0,43). La tabla 1 ilustra los análisis de subgrupos (poblacionales, por tipo de producto que contiene arándano y por dosis diaria).

Tabla 1. Resultados de por subgrupo poblacional, por tipo de producto y por dosis diaria de arándano.

\begin{tabular}{|c|c|c|c|c|c|}
\hline & & \multicolumn{2}{|c|}{$\begin{array}{l}\text { Tasa de incidencia acumulada de infecciones } \\
\text { urinarias por grupo }\end{array}$} & \multirow[t]{2}{*}{ Heterogeneidad $\mathrm{I}^{2}$} & \multirow[t]{2}{*}{$\begin{array}{c}\mathrm{RR} \\
\text { (IC95\%) }\end{array}$} \\
\hline & & $\begin{array}{c}\text { Arándano } \\
\text { (intervención) }\end{array}$ & Control & & \\
\hline \multirow{5}{*}{$\begin{array}{l}\text { Subgrupo } \\
\text { poblacional }\end{array}$} & Mujeres con ITU recurrente & $27 / 150$ & $34 / 100$ & 0 & $0,53(0,33$ a 0,83$)$ \\
\hline & Pacientes con vejiga neurogénica & $39 / 150$ & $51 / 157$ & 0,37 & $0,80(0,57$ a 1,14$)$ \\
\hline & Niños & $5 / 27$ & $18 / 27$ & $\mathrm{ND}$ & $0,28(0,12$ a 0,64$)$ \\
\hline & Ancianos & $7 / 187$ & $14 / 189$ & ND & $0,51(0,21$ a 1,22$)$ \\
\hline & Embarazadas & $4 / 125$ & $0 / 63$ & ND & $4,57(0,25$ a 83,60$)$ \\
\hline \multirow[t]{2}{*}{ Tipo de producto } & Jugo & $26 / 404$ & $53 / 344$ & 0,02 & $0,47(0,30$ a 0,72$)$ \\
\hline & Cápsulas o tabletas & $37 / 135$ & $48 / 142$ & 0,57 & $0,79(0,44$ a 1,49$)$ \\
\hline \multirow{2}{*}{$\begin{array}{l}\text { Frecuencia de la } \\
\text { dosis }\end{array}$} & Dos o más dosis al día & $42 / 360$ & $54 / 306$ & 0,18 & $0,58(0,40$ a 0,84$)$ \\
\hline & Una dosis al día & $21 / 62$ & $24 / 73$ & ND & $1,03(0,64$ a $-1,66)$ \\
\hline
\end{tabular}

ND: no disponible. ITU: infección del tracto urinario.

\section{Conclusiones}

El consumo de arándanos fue efectivo para la prevención de ITU, fundamentalmente en mujeres con ITU recurrente y en niños. Sin embargo los resultados de este metanálisis deben interpretarse con precaución dada la heterogeneidad de los estudios analizados.

Fuente de financiamiento/conflicto de interés de los autores: No referida

\section{Comentario}

El $30 \%$ de las mujeres presenta en algún momento de su vida síntomas de infección urinaria, desarrollando recurrencia un $20 \%{ }^{1}$. El $90 \%$ de las recurrencias se debe a una reinfección exógena y es excepcional la presencia de anormalidades urológicas. Como medidas eficaces y seguras en la prevención de ITU podemos aconsejar a las mujeres a evitar las conductas que aumentan el riesgo de recurrencia y el uso de la profilaxis antibiótica. El arándano rojo (cranberry) es el fruto del Genus vaccinium y se suele indicar en la prevención de las ITU debido a su capacidad in vitro de inhibir la adhesión de las bacterias uropatógenas a las células uroepiteliales². Sin embargo, no existe suficiente evidencia sobre su eficacia preventiva, ni consenso sobre cuales son la dosis y la duración óptima de su tratamiento. Como afirman sus autores, los resultados de este metanálisis deben interpretarse con precaución dado que se documentó una moderada heterogeneidad entre los diferentes ensayos incluidos: diferentes definiciones de ITU, y variabilidad en el tipo de producto y dosis utilizada. Vale destacar que recientemente fue publicada una actualización de la Colaboración Cochrane ${ }^{3}$ que incluye a este metanálisis, que documentó que los productos de arándano no reducen significativamente la recurrencia de ITU en mujeres con ITU recurrente (RR 0, 74 IC 0,42 a 1,31), desaconsejando su uso en forma prolongada.

\section{Conclusiones del comentador}

No hay suficiente evidencia para recomendar en forma sistemática el arándano en la prevención de ITU en atención primaria. Esto no debiera demorar nuestro accionar cotidiano en la prevención de los factores de riesgo biológicos y conductuales que predisponen las ITU y en el uso de profilaxis antimicrobiana en dosis bajas en las situaciones que así lo requieran.

David Colica [ Servicio de Medicina Familiar y Comunitaria. Hospital Italiano de Buenos Aires david.colica@ hospitalitaliano.org.ar ] *Ver glosario Cólica D. Controvertida evidencia sobre la eficacia del arándano para la prevención de infecciones urinarias. Evid Act Pract Ambul Oct-Dic 2013; 16(4):127. Comentado de: Chih-Hung Wang y col. Cranberry- Containing products for prevention of urinary tract infections in susceptible populations. A systematic review and Meta-analysis of randomized controlled trials. Arc.Intern.Med. 2012; 172 (13): 998-996. PMID: 22777630.

\section{Referencias}

1. Kopitowski K. Infecciones Urinarias. Capítulo 178. Pág. 1397-1400. Rubinstein A, Terrasa S y col. Medicina Familiar y Práctica Ambulatoria. 2da edición, Buenos Aires, Médica. Panamericana, 2006. ISBN 950-06-1878-8-84-7903-433-5.

2. Kontokiari T, Sundqvist K, Nuutinen M. Randomised trial of cranberry-lingoberry juice and Lactobacillus GG drink for the prevention of urinary tract infections in women. BMJ. $2001 ; 322$ (7302): 1571. 3. Jepson RG, Williams G, Craig JC. Cranberry for preventing urinary tract infections. Cochrane Database Systematic Reviews 2012, Issue 10. Art. No.: CD001321. DOI: 10.1002/14651858.CD001321.pub5. 